\title{
IDENTIFICAÇÃO DA SUSCEPTIBILIDADE AOS PROCESSOS EROSIVOS POR MEIO DA ANÁLISE GEOTÉCNICA EM UM TALUDE ARTIFICIAL DE CORTE NO BAIRRO DO ROSÁRIO, AREADO-MG
}

\author{
Jéssica Santos Braz ${ }^{(a)}$, Lineo Aparecido Gaspar Junior ${ }^{(b)}$ \\ (a)Instituto de Ciências da Natureza, Universidade Federal de Alfenas, jessicabrareado@hotmail.com \\ (b)Instituto de Ciências da Natureza, Universidade Federal de Alfenas, lineo.gaspar@unifal-mg.edu.br
}

\section{Eixo: SOLOS E PAISAGENS}

\begin{abstract}
Resumo
Para se compreender a erodibilidade é necessário considerar os fatores climáticos, topográficos, cobertura vegetal e significativamente as propriedades do solo. Assim, mudanças nestas condições, principalmente relacionadas à ação antrópica, caracterizam-se potencialmente como áreas com susceptibilidade à ocorrência de processos erosivos, como é o caso do local em Areado-MG. A área de estudo foi submetida à extração de cascalho e para isso a cobertura vegetal foi removida e a geometria do terreno modificada, o que desencadeou o processo de denudação acelerada. Dessa maneira, objetiva-se realizar a análise geotécnica para identificação das propriedades mecânicas, físicas, química e mineralógica do solo, além das condições (geomorfológicas e pedológicas), fazendo relação à produção cartográfica com fins de evidenciar tais susceptibilidades. Os resultados permitem concluir que as propriedades de um solo arenoso siltoso juntamente com as relações climáticas, geológicas, topografia, pecuária, mineração, escassez de cobertura vegetal acentuaram a problemática, indicando um planejamento urbano ambiental emergencial.
\end{abstract}

Palavras-chave: análise Geotécnica, erodibilidade, risco, degradação do solo, talude artificial.

\section{1- Introdução}

A denudação ocorre naturalmente em toda a superfície terrestre e faz parte, por sua vez, da dinâmica da modelagem constante da paisagem, ou seja, o processo recorrente está relacionado com o equilíbrio de remoção de material desagregado com a formação do mesmo; todavia com as atividades desenvolvidas pela a ação humana, caracterizadas pela expansão urbana, exploração mineral, supressão da cobertura vegetal dentre outros fins, desencadeiam uma ruptura do sistema de equilíbrio da formação pedogenética, provocando, portanto, uma erosão acelerada, comprometendo, dessa maneira, a integridade dos recursos naturais no sistema ambiental, principalmente o solo. Assim, para compreender a erodibilidade é necessário considerar os fatores climáticos, topográficos, cobertura vegetal e significativamente as propriedades do solo. Dessa maneira, mudanças nestas condições, principalmente relacionadas à ação antrópica, intensificam o processo caracterizando potencialmente como áreas com susceptibilidade à ocorrência de erosão, como é o caso da área de estudo em AreadoMG. O local em análise no presente trabalho, localizado no bairro do Rosário foi submetido a perturbações mediante a exploração descontrolada de cascalho pelas competências públicas, originando um talude de corte artificial com escassez de cobertura vegetal, exposto, assim, à ação dos 
agentes exógenos, potencializando a ação erosiva. Tendo em vista que a problemática se encontra na mancha urbana, deve-se considerar que há uma população ao entorno da mesma, apresentando uma condição de risco, já que a área possui histórico de escorregamentos, sem nenhuma iniciativa de conter as problemáticas desenvolvidas no progresso das feições erosivas.

Assim, pretende-se discutir neste presente trabalho de acordo com a análise geotécnica do solo do local em estudo, como as condições das propriedades do solo, somadas à condição climática, geológica, pedológica, topográfica, a ação antrópica admitida na mudança da geometria do terreno, pecuária no local, remoção da cobertura vegetal influi na susceptibilidade dos solos em desenvolver um processo de erosão hídrica por fluxo de água superficial concentrado da chuva, apontando uma problemática emergencial para a população ao entorno, exigindo, dessa forma, um planejamento urbano ambiental. Além disso, é vital o apontamento do dado estudo como um recurso de consulta municipal para a recuperação da dada área.Considerando, assim, não apenas o aspecto natural, mas também a relação intrínseca do homem e a natureza em uma abordagem sistêmica que caracteriza a ação antrópica como agente transformador da paisagem no sistema ambiental.

Para tanto, fez-se necessário utilizar ensaios geotécnicos em laboratório e campos para a identificação das condicionantes das propriedades em análise das amostras coletadas distribuídas de forma uniforme pela a encosta; fotografias aéreas com pipas para a verificação da geometria do talude artificial de corte; produção de material cartográfico para a espacialização das fontes pedológicas e geológicas, tal como as entrevistas com a população e com as competências públicas com fins de compreender a interação das mesmas com a problemática em enfoque, visto que a ação da extração atual mesmo que em menores proporções não foi interrompida e a existência de depósitos de lixo realizados pela a própria população ao entorno da problemática, colocando em evidência a produção do espaço geográfico em relação inúmeras interações, propósitos refletidas na mudança da paisagem pela a ação antrópica.

\section{2-A erodibilidade dos solos: Fatores condicionantes}

A susceptibilidade de um solo à erosão é conhecida como erodibilidade. Segundo Bertoni \& Lombardi Neto (1990) quando o processo erosivo se apresentar em ambientes com cobertura vegetal e com a escassez da influência das forças determinantes da ação antrópica se caracteriza como processo natural geológico, tal como Grilo \& Enami (2008) que refere-se à erosão natural como o processo sem a intervenção modificadora do homem, dentro de um sistema integrador de agentes naturais que desencadeia o desgaste da superfície terrestre. Em contrapartida, a erosão antrópica ou acelerada determina-se pela a ocupação irregular do solo ou até mesmo com práticas induzidas pelo homem ao solo que promovem o desequilíbrio dos condicionantes relacionados à erodibilidade. 
Em relação ao grau de erodibilidade, o mesmo não é homogêneo em todos os tipos de solos; tal condição é fundamentada de acordo com suas características de textura, estrutura, permeabilidade, densidade que por sua vez apresentam sobre a resistência dos agregados em relação a ruptura dos mesmos pelo o impacto das gotículas de água da chuva definindo sobre a capacidade erosiva do escoamento superficial da água, que segundo Bertoni \& Lombardi Neto (1990) tais características definem sobre a capacidade da água de infiltrar ou escoar superficialmente. Além disso, o potencial de remoção de partículas pelo o agente hídrico também é definido pela a condição da intensidade da chuva e durabilidade, a topografia do local, a presença de cobertura vegetal tal como o uso e ocupação do solo. Assim, como ressalva:

A erosão é causada por forças ativas, como as características da chuva, pois, a água pluvial exerce sua ação erosiva sobre o solo pelo impacto das gotas, que caem com velocidade e energia variáveis, dependendo do seu diâmetro, e pelo escoamento da enxurrada, a qual tem sua velocidade e volume variando segundo a declividade, o comprimento do declive do terreno e a capacidade que tem o solo de absorver água; e por forças passivas, como a resistência que exerce o solo à ação erosiva da água (determinada por diversas de suas características ou propriedades físicas e químicas) e a densidade da cobertura vegetal. Para buscar soluções para esse problema, é necessário pesquisar as inter-relações dos fatores contribuintes. Ainda que alguns desses fatores não se possam modificar diretamente, todos podem ser controlados, compreendendo-se bem a forma como atuam. (BERTONI; LOMBARDO NETO, 1990)

Tais condicionantes das propriedades do solo, são importantes análises para a verificação geotécnica sobre a capacidade de escoamento da água da chuva. Assim, solos de textura arenosa siltosa, nas condições de pouca quantidade de matéria orgânica e sem a cobertura vegetal, tal como uso inadequado dos recursos naturais, desencadeiam um processo de menor adesão dos agregados no solo, fazendo que os grãos dos mesmos percam a aglutinação, facilitando o processo de ruptura e remoção dos desagregados pelo o escoamento da água. Assim, como refere o autor:

Propriedades texturais e estruturais também influenciam a interação com a chuva (solo-chuva) e, consequentemente, sua capacidade de infiltração. A taxa de equilíbrio de infiltração é uma função da porosidade total, a proporção relativa de macroporos, e a estabilidade e continuidade de macroporos, além do que, os biocanais criados por raízes deterioradas e pela fauna do solo têm maiores efeitos na capacidade de infiltração (LAL, 1988).

Assim, em relação à área de estudo, a extração de cascalho em inúmeros municípios é comum principalmente no que se refere ao interesse de pavimentação ou para uso em estradas rurais para facilitar a circulação de veículos. Todavia, para tal admissão grande parte da cobertura vegetal é removida deixando a área suscetível a desencadear com mais intensidade a perda de solo no desenvolvimento dos processos que envolvem a erodibilidade, caracterizando ,dessa maneira, a erosão acelerada. Dentro disso, a supressão da vegetação apresenta uma vulnerabilidade das partículas do solo em resistir o impacto da água da chuva, já que a resistência do material é rompida mais facilmente, por isso a necessidade da proteção natural como meio de diminuir as forças de tração no transporte do material inconsolidado, conforme os autores: 


\section{OS DESAFIOS DA GEOGRAFIA FÍSICA NA FRONTEIRA DO CONHECIMENTO \\ Instituto de Geociências - Unicamp Campinas - SP \\ 28 de Junho à 02 de Julho de 2017}

A proteção à erosão consiste essencialmente de : (1) diminuir as forças de tração ou de arrasto, diminuindo a velocidade do fluxo d'água sobre a superfície ou dissipando a energia da água em uma área protegida,e (2) aumentar a resistência à erosão através da proteção/reforço da superfície com uma cobertura adequada ou pelo aumento da força de ligação entre as partículas.(GUERRA, A. J. T.; ALMEIDA, Josimar Ribeiro de ; ARAUJO, G. H. S. 2005, p. 82)

A topografia também é condicionante primordial no que se refere ao desencadeamento da erodibilidade no solo, pois o mesmo é um fator natural que implica sobre a velocidade de escoamento da água e a capacidade da mesma de remoção das partículas; sendo a declividade e o comprimento da encosta fatores importantes na análise da influência dos processos erosivos. Dessa maneira, a ação do homem, deve ser compreendida como um condicionante que modifica as condições naturais do meio, assim, causando desequilíbrio nos processos naturais. Quando a ação antrópica modifica impreterivelmente sem nenhum planejamento adequado a geometria do terreno, o mesmo potencializa a ação do agente pluvial, pois a mesma ganha significativamente velocidade na remoção das partículas desagregadas, ainda mais somadas com uma condição inexistente de captura hídrica, pois segundo IPT (1989) e BITTAR et al. (1990) a precariedade de estruturas de sistemas de drenagens pluviais desencadeia a evolução de processos de erosão urbana. Assim, como apresenta a área em estudo onde a geometria da encosta foi alterada de forma abrupta e não há sistema de captura da água da chuva, somada ainda que a encosta se apresenta com uma geometria convexa o que potencializa ainda mais o processo.

\section{3- Caracterização física da área em estudo}

A área de estudo está localizada no Munícipio de Areado, situado no sudoeste do estado de Minas Gerais, na Microrregião de Alfenas-MG (Figura 1). O munícipio compreende uma área no total de 281 $\mathrm{km}^{2}$ com uma posição geográfica de $21^{\circ} 21^{\prime} 30^{\prime \prime}$ latitude sul - $46^{\circ} 09^{\prime} 20^{\prime \prime}$ longitude oeste, à altitude máxima de 801 metros. O clima é o temperado, chove mais no verão que no inverno e possui as estações de inverno e verão bem definidas. Assim, segundo a prefeitura de Areado (2003) o clima é classificado como Cwa de acordo com a Köppen-Geiger, com temperatura média de $24.6{ }^{\circ} \mathrm{C}$, máxima de $30^{\circ} \mathrm{C}$ e mínima de $13^{\circ} \mathrm{C}$, apresentando a média anual de pluviosidade de $1488 \mathrm{~mm}$. 


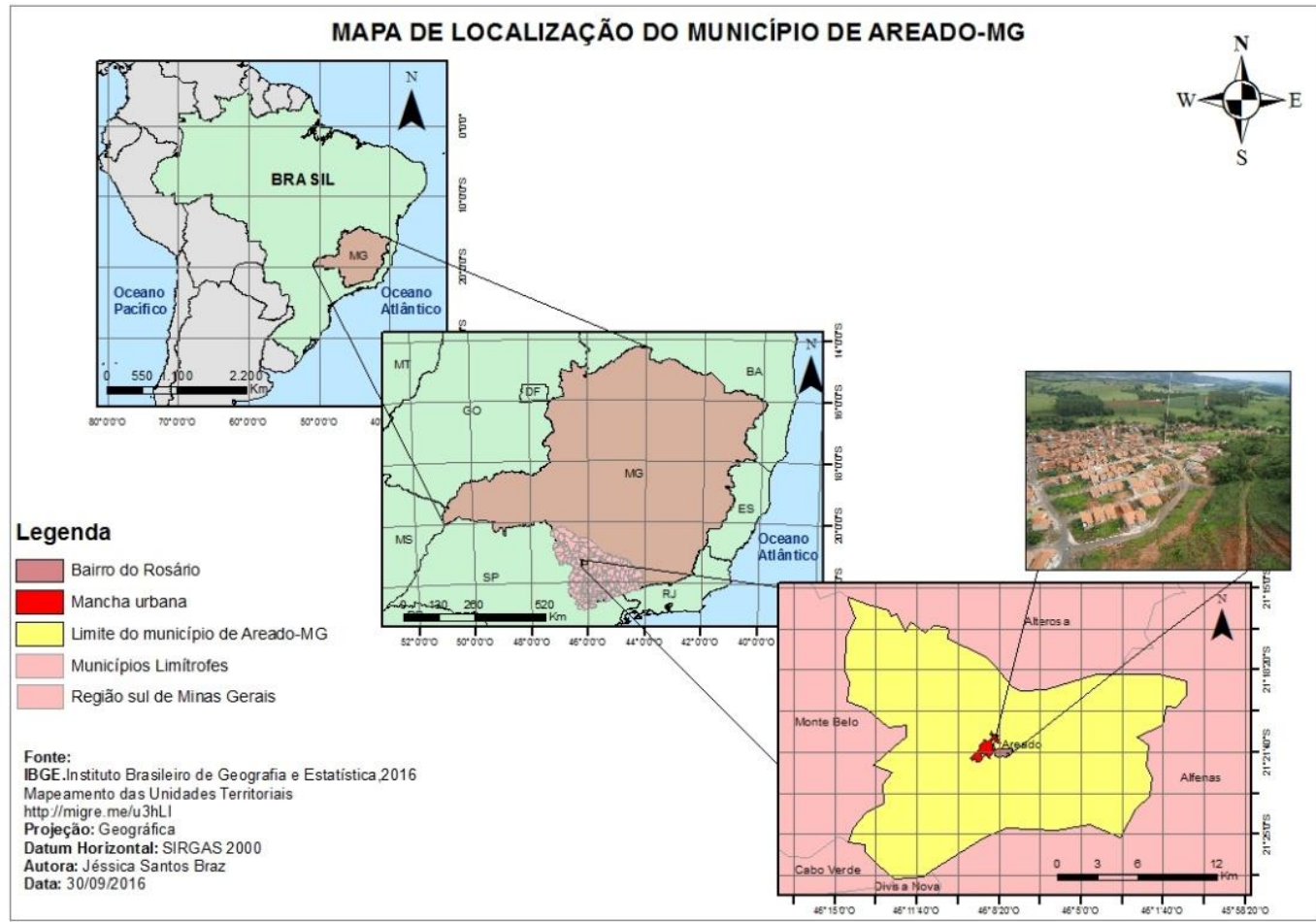

Figura 1: Mapa de localização do município de Areado-MG, no sul de Minas Gerais; e do bairro do Rosário onde se localiza a área de estudo, elaborada pela a autora deste trabalho.

O município em questão pertence geologicamente ao complexo Guaxupé (Fonseca et al. 1979), este correspondente a um bloco limitado a norte pela zona de cisalhamento Campo do Meio, a sul pela Zona de Cisalhamento de Ouro Fino e a leste pelo Supergrupo Alto Rio Grande (Hasui \&Oliveira, 1984). A (figura 2) demonstra os tipos de litologia predominantes na estrutura, de modo geral, podem ser agrupadas em ortoderivadas e paraderivadas (Grupo Caconde), que foram submetidas a metamorfismo de alto grau em fácies de granulito e anfibolito, que podem ser representadas por hiperstênio-granulitos (charnoquitos), granulitos básicos, gnaisses graníticos bandados, rochas metabásicas e metaultrabásicas (Hasui et al., 1989). O metamorfismo regional que atingiu a área é do tipo intermediário. O Grau de metamorfismo aumenta desde as fácies de xisto verde médio, com biotita, cloritóide, e localmente, cianita, passando por fácies xisto verde alto com granada (almandina) até as fácies de anfibolito com estaurolita, plagioclásio, cianita e silimanita. 


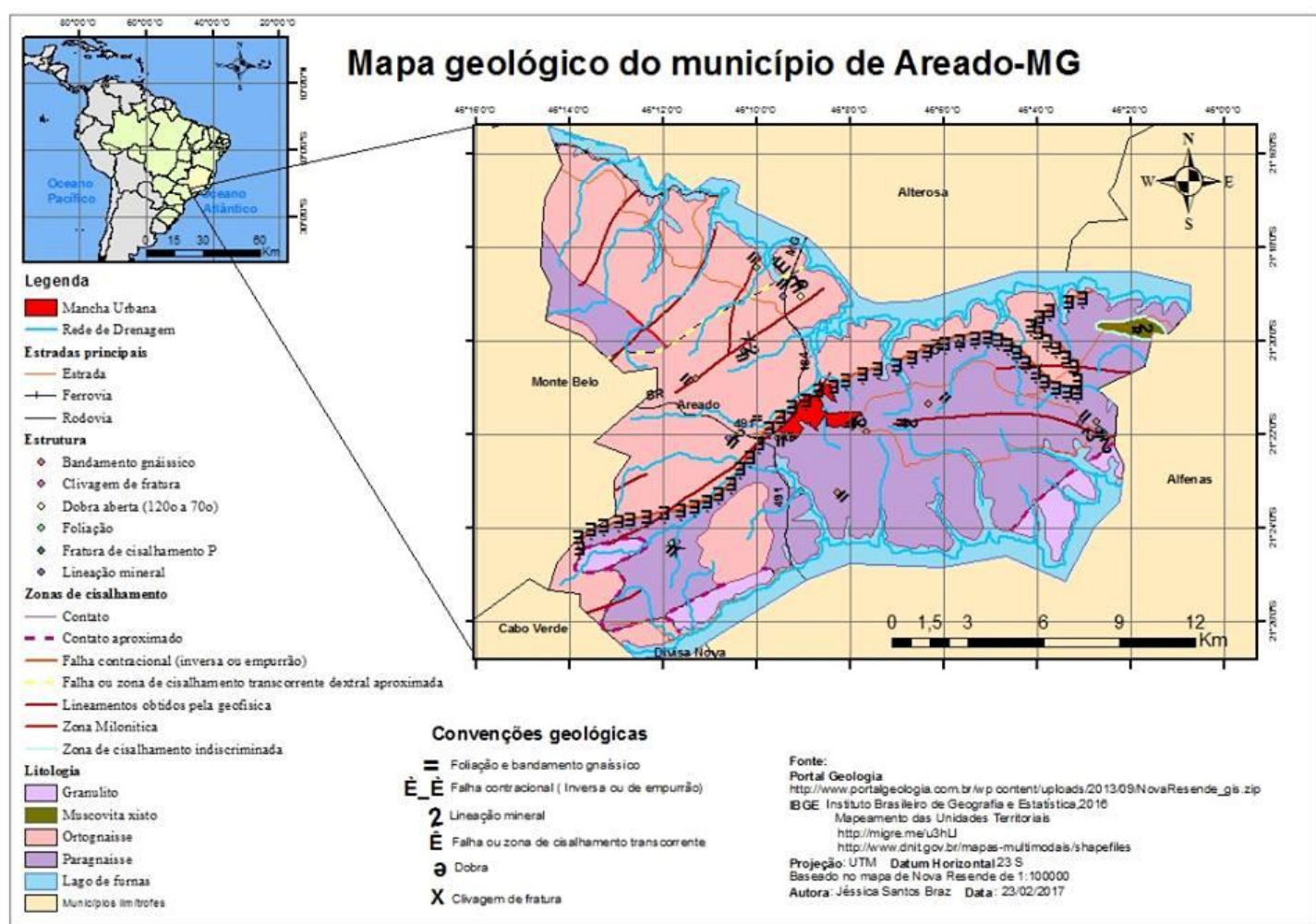

Figura 2: Mapa de geológico do município de Areado-MG, elaborada pela a autora deste trabalho.

$\mathrm{Na}$ área de estudo especificadamente, os recursos presentes são caracterizados como gnaisses graníticos e horblenda gnaisse, com alta presença de minerais silicáticos dentre eles: biotita, muscovita, quartzo e anfibolitos. Dessa maneira, a alteração dos componentes mineralógicos juntamente com as relações climáticas e o longo período de exposição da área implica na ocorrência de um material arenoso siltoso. Segundo Gaspar, Junior (2012, p.404-411) regionalmente verifica-se que: " Em suas características pedológicas, há a predominância de solos com perfil litológico bem espesso (Latossolo) vermelho e textura argilosa, desenvolvidos sobre rochas pré-cambrianas com alto grau de metamorfismo". Assim, o município apresenta uma pedologia predominantemente de Latossolo Vermelho e argissolo (Figura 3), dado pela a alteração do embasamento rochoso metamórfico, principalmente os gnaisses graníticos. 


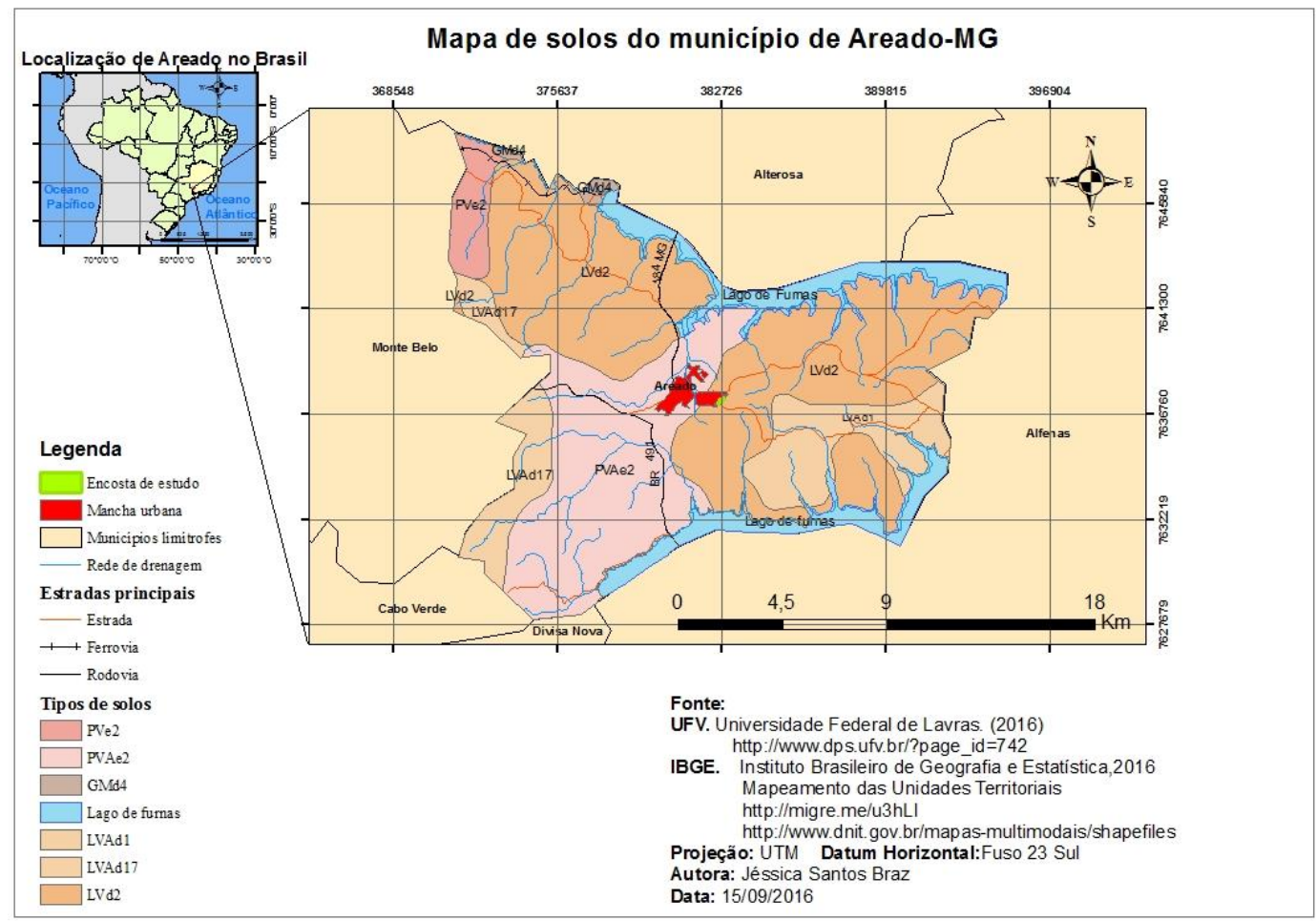

Figura 3: Mapa de solos do município de Areado-MG, elaborada pela a autora deste trabalho

\section{4- Procedimentos metodológicos}

A realização do trabalho foi fundamentada primeiramente em revisão de literatura para a compreensão dos condicionantes que afetam a susceptibilidade aos processos erosivos, além disso, as análises em laboratório, trabalho de campo para a coleta de amostragem e análise das feições morfodinâmicas, foram realizados cinco coletas disseminadas por toda a encosta (Figura 4)-, análise de fotografias áreas com pipas para a compreensão da geometria e extensão do talude em enfoque, apresentando 12 metros de altura e 128 metros de extensão. Além disso, foi realizada a proximidade por meio de diálogos com a população e as competências públicas no município em relação à interação dos mesmos com a problemática.

Para caracterização do material inconsolidado e litologia-estrutural a metodologia utilizada foi baseada nos Ensaios Químicos e Geotécnicos em Solos (Gaspar, Junior, 2011), no Manual de métodos de análise de solo da Embrapa (1997) e no Manual de descrição e coleta de solo no campo de Santos et al. (2005). Os ensaios foram realizados no Laboratório de Geociências da Universidade Federal de Alfenas UNIFAL-MG.

Os atributos metodológicos são divididos em:

- Ensaios Físicos do solo em campo (Cor, textura, estrutura, porosidade cerosidade, consistência, plasticidade, pegajosidade, cimentação, nódulo e concreção).

- Distribuição Granulométrica Seca; 
- Análise Mineralógica em Lupa;

- Índices de Umidade;

- Índices de Liquidez;

- Índice de Plasticidade;

- Teor de Carbono Orgânico;

- Índice de pH (Potencial Hidrogeniônico);

- Índice de Infiltração de Água no Solo;

- Índices Físicos do Solo (relação das condições físicas com massa e volume)

- Material cartográfico das feições pedológicas e geológicas;

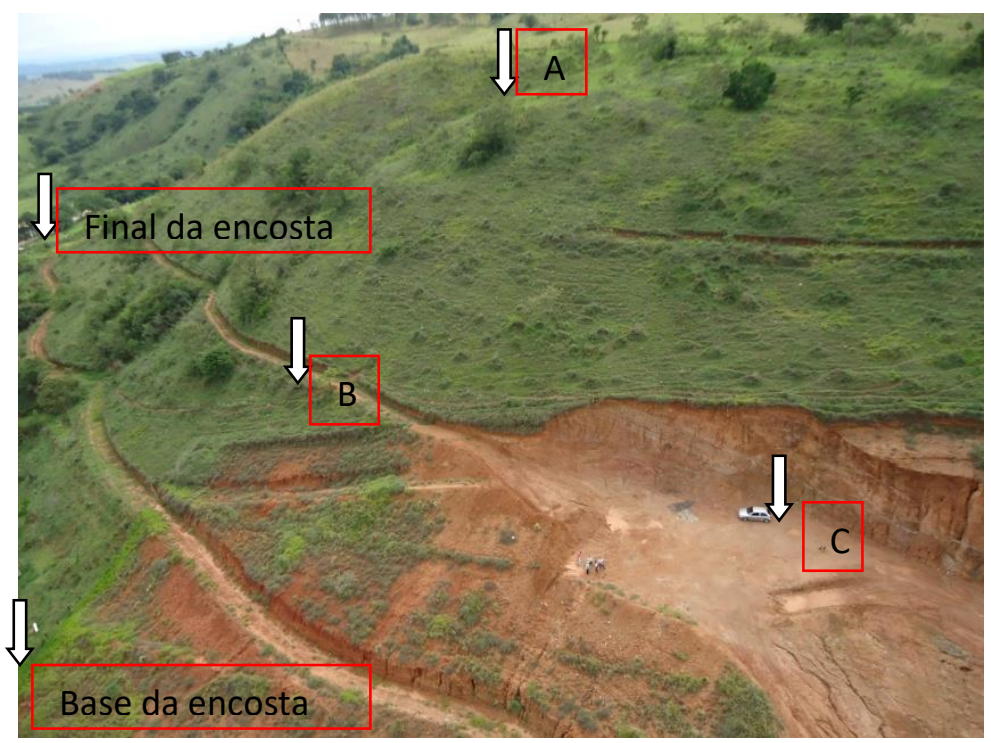

Figura 4: A extensão do talude de corte por fotografia aérea com pipa, apontando os horizontes do solo de coleta de amostragem. Fonte de BRANQUINHO, Evânio, dezembro de 2016.

\section{5- Resultados}

Por meio dos trabalhos de campos realizados, análises geotécnicas nos cinco pontos de coletas pela encosta e material cartográfico do município, avalia-se a fragilidade do solo diante de suas características físicas, mecânicas e mineralógicas, constatando-se que o solo da área em questão, apresenta uma textura arenosa siltosa e estrutura granular e subangular, oriundos da alteração predominantemente dos gnaisses graníticos. Dessa maneira, o índice de infiltração no solo é, em geral, rápido (Figura 5) influenciado pelas suas propriedades granulométricas, o que, por sua vez, é influenciada pela granulometria média a grossa que prevalece (Figura 6) alta concentração de partículas com dimensão entre $10 \mathrm{~mm}$ e $30 \mathrm{~mm}$, resultando, portanto, em um alto índice de porosidade (Figura 7). Tais condições verificadas, permitem uma maior percolação da água pelos poros, promovendo dessa maneira, em uma condição climática de alta intensidade pluviométrica em menor espaço temporal, uma menor adesão entre os grãos pela lâmina de água, diminuindo o atrito entre as 
partículas, potencializando o processo de remoção de sedimentos, ou seja, a intensificação da erodibilidade.

O teor de carbono orgânico influencia sobre a capacidade de ruptura dos agregados, ou seja, o mesmo está associado sobre a facilidade ou dificuldade da partícula ser afetada pelo o impacto da gotícula de água. As análises das amostras coletadas apontaram para um baixo teor de carbono orgânico, na faixa de entre 3 a 5\% (Figura 8) e de argilo minerais, o que denota uma baixa plasticidade do material, permitindo que a coesão entre seus minerais seja menor, formando poucos torrões, sendo mais suscetível à erosão. Assim, a matéria orgânica é de suma importância para a aglutinação dos agregados, de acordo com Greenland et al. (1975) aput GUERRA, A.J.T. et. al. (Orgs.) solos com menos de 3,5 \% de matéria orgânica são solos extremamente instáveis, dessa maneira, quanto menor a quantidade de matéria orgânica maior a instabilidade do solo.

O tipo de solo no local em estudo é o Latossolo Vermelho com detritos, caracterizando um solo bem desenvolvido predominantemente. O horizonte A (Topo da encosta) evidencia um Neossolo, pouco espesso, caracterizando maior potencial de transporte de material, devido o escoamento superficial intensivo, dado a declividade pela a ação da força gravitacional, somado também à uma geometria convexa da encosta. O potencial hidrogeniônico é uma análise que avalia a acidez, deste caso, do solo; a acidez pode resultar dos elementos químicos presentes na amostra (mineralogia), do ambiente de formação, dentre outros aspectos. As análises do solo apontaram pH entre 5,0 e 6,2 o que caracteriza um solo ácido (Figura 9), com visível predominância de teor de ferro, sendo assim, um pH extremamente preocupante, o que por sua vez demonstra um solo instável, já que o alto teor de ferro aponta para a diminuição da presença de cálcio, cujo representa um importante aglutinador dos grãos, intensificando, assim, o processo de denudação. Além disso, é importante considerar que as feições erosivas acompanham certa orientação seja ela por zonas de cisalhamento ou xistosidades das rochas. Verificam-se algumas evidências erosivas de amplitude significativas próximas a alguns afloramentos rochosos, tal como evidenciadas pelo o próprio mapa geológico do município que aponta a orientação da falha em relação à direção das camadas de rochas.

Em relação à análise da interação intrínseca com a população no entorno, verifica-se muito lixo no local e a falta de informação abordada em relação à problemática. A prática de pecuária no local e os veículos transportadores do cascalho contribuíram com a compactação do solo e a aceleração do processo erosivo, já que o índice de vazios demonstra baixo diante das análises efetuadas.

Assim, mediante a caracterização do material de análise caracterizando uma areia siltosa (SM), um cascalho siltoso (GM), e de um cascalho grosso (GP) de acordo com a hierarquia de erodibilidade baseada no sistema de Classificação Integrado de Solos (do mais erodível para o menos erodível), evidencia- se que as propriedades de um solo arenoso siltoso oriundo da alteração de gnaisses graníticos extremamente intemperizados, com baixo teor de carbono orgânico, material de 
XVII Simpósio Brasileiro

de Geografia Fisica Aplicada

I Congresso Nacional

de Geografia Física

\section{OS DESAFIOS DA GEOGRAFIA FÍSICA NA FRONTEIRA DO CONHECIMENTO \\ Instituto de Geociências - Unicamp \\ Campinas - SP \\ 28 de Junho à 02 de Julho de 2017}

granulometria média a grossa e escassez de cobertura vegetal caracteriza-se como um material em condições de vulnerabilidade ambiental apontando para condições de fragilidade do local, assim como aponta a (tabela 1). Dessa forma, os resultados verificados apontam para um emergencial planejamento urbano ambiental para que a população ao entorno não venha a correr sérios riscos.

Tabela I- Tendência de erodibilidade do solo

- É baixa em materiais grossos

- É alta em siltes e areais finas

- Diminui com o aumento de argila e matéria orgânica

- Diminui com o aumento da cobertura vegetal e do teor de umidade anterior

- Aumenta com o aumento da taxa de adsorção de sódio e com a diminuição da força iônica da água.

Fonte: Adaptada de Gray e Sotir ( 1996) aput

GUERRA, A. J. T.; ALMEIDA, Josimar Ribeiro de ; ARAUJO, G. H. S.( 2005, p.84)

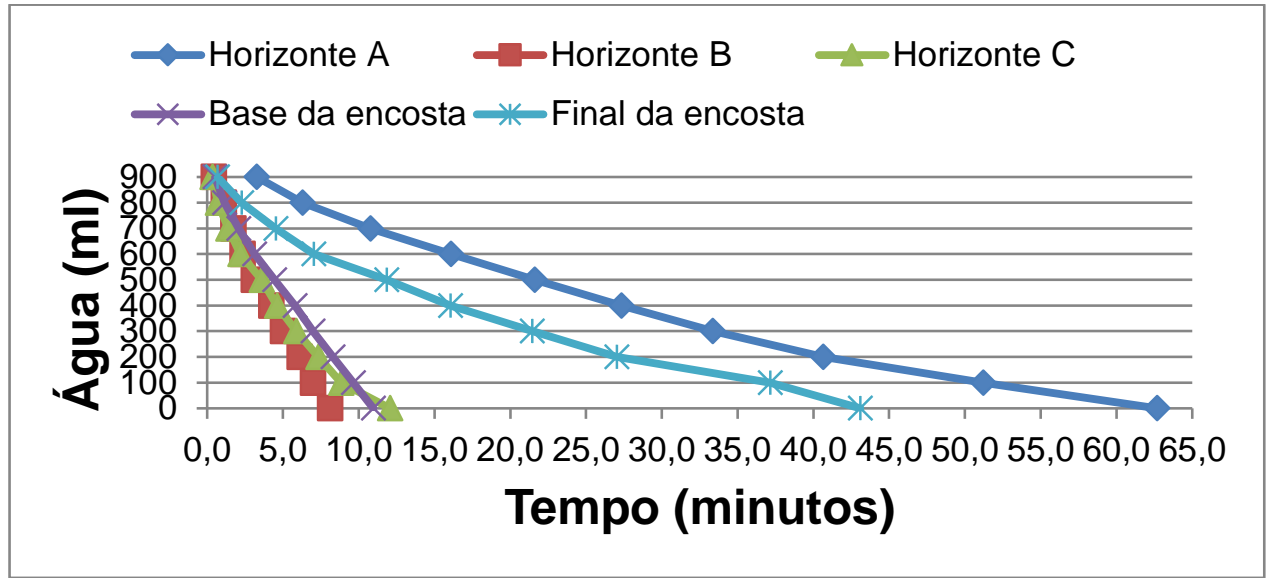

Figura 5: Taxa de infiltração no solo, fonte própria, 2016

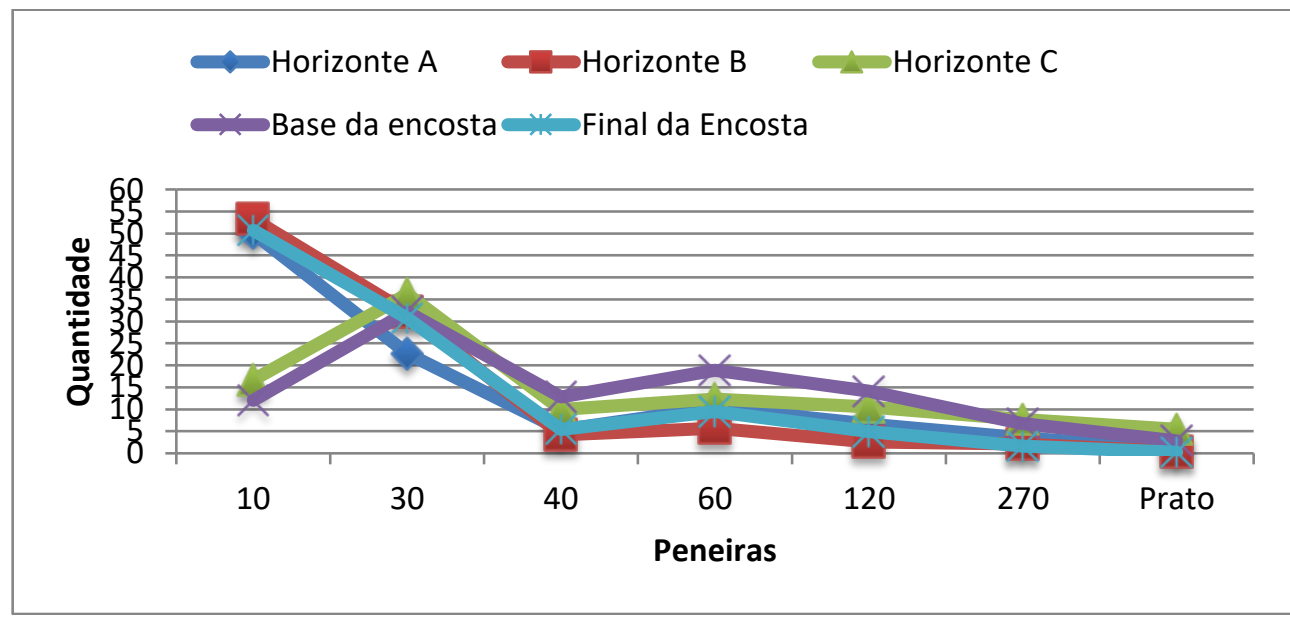

Figura 6: Distribuição granulométrica seca, fonte própria, 2016 


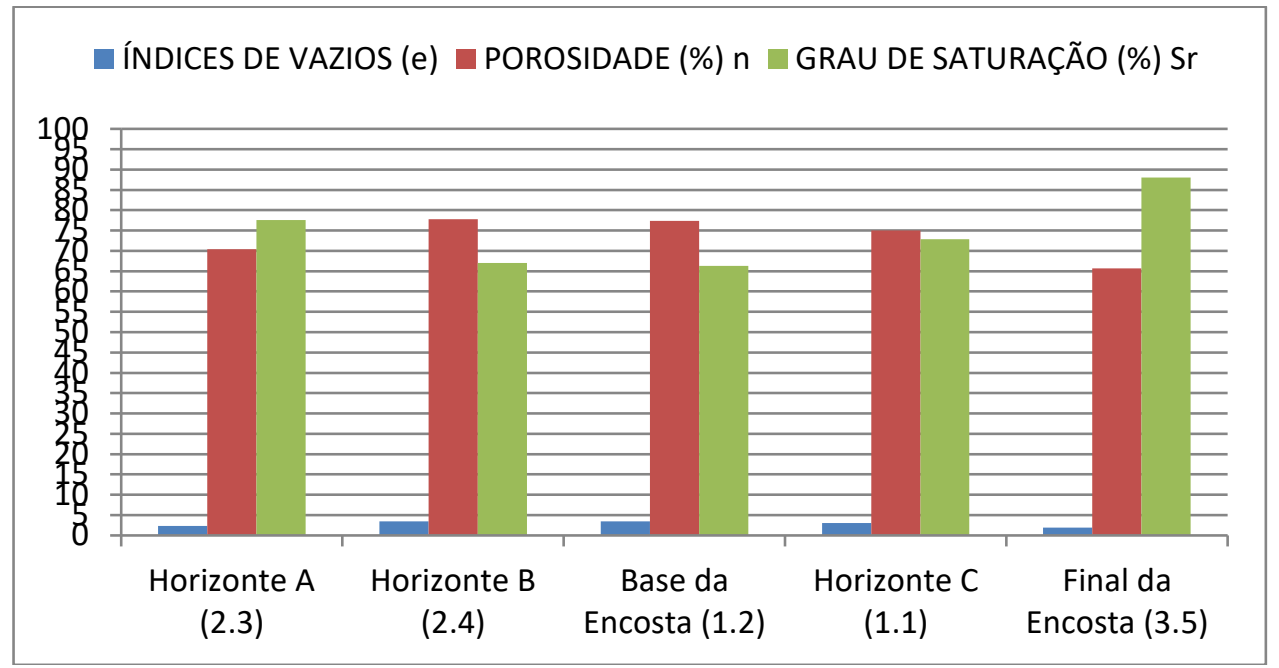

Figura 7: Índices físicos do solo, fonte própria, 2016
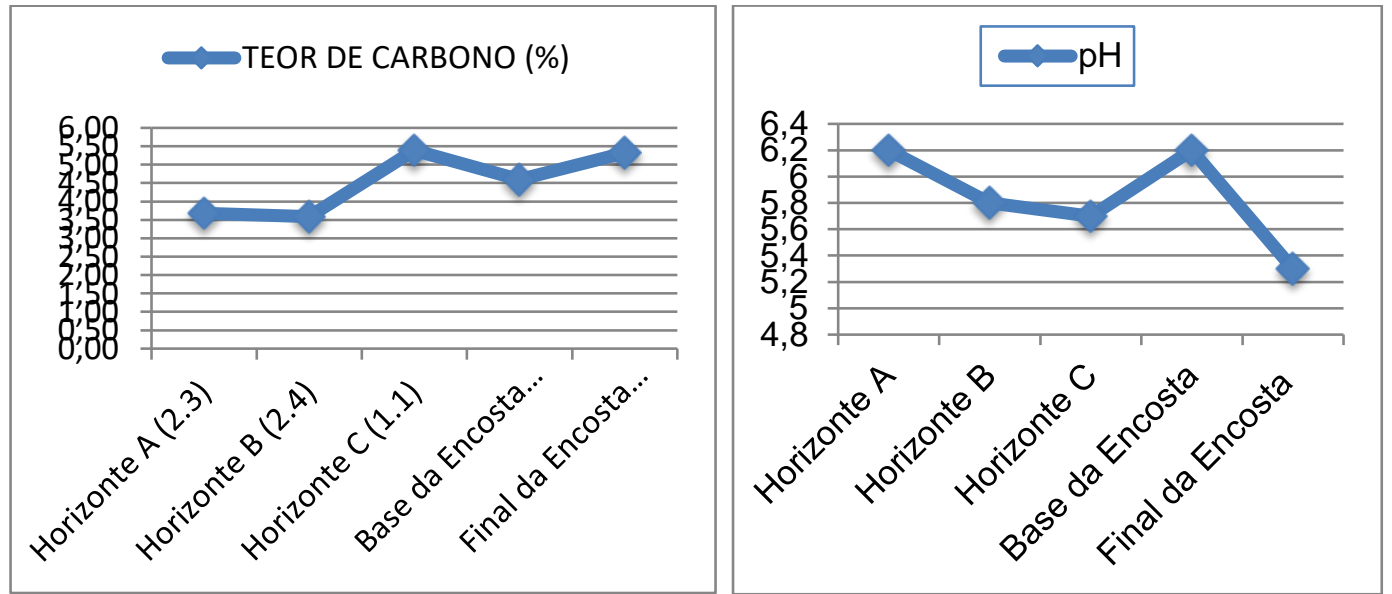

Figura 8: Teor de carbono orgânico, fonte própria, 2016 Figura 9: Potencial hidrogeniônico, fonte própria, 2016

\section{6- Conclusão}

Diante dos dados evidenciados conclui-se neste trabalho que a área degradada apresenta propriedades físicas, químicas e mineralógicas potenciais para a erodibilidade do local. A área é desconectada com a rede hidrográfica, assim o processo erosivo é realizado basicamente pelo o fluxo da água da chuva; considerando que foram admitidas intervenções mínimas para conter estes problemas e que nenhuma alternativa foi providenciada para conter o processo de erosão, até o momento pelos agentes responsáveis, e nem mesmo estruturas de captura da rede pluvial no planejamento urbano em relação à problemática ambiental. Assim, diante de tais características alarmantes afirma-se a plena necessidade de um planejamento de estabilização da encosta para que haja uma contenção do processo erosivo vigente, para que o mesmo não se apresente como um potencial risco ambiental e social. 
Dessa forma, avalia-se finalmente com este estudo que as relações climáticas juntamente com as práticas de pecuária no local, a mineração e a escassez de cobertura vegetal auxiliam na intensificação das condições que acentuam a problemática. Visando que não existem estudos desse gênero na área em questão, o presente trabalho pode ser utilizado como uma referência para os setores públicos na tomada de decisões convenientes para a estabilização da problemática. Assim, propõem-se o método geotécnico de retaludamento no local como meio de diminuir o impacto da velocidade da água da chuva no solo, e a cobertura vegetal na área prevalecendo a mata nativa como meio de estabilização e equilíbrio na condição do sistema ambiental. Devemos considerar que o município é formado por um solo extremamente arenoso siltoso, o que por sua vez de acordo com suas propriedades são mais suscetíveis a erodibilidade, por isso evidencia-se a emergência de um plano urbano/ambiental para estas obras urbanas no município mantendo a estabilidade do equilíbrio de seus fatores com fins de benefício que não considera apenas o meio ambiente, mas também o social em uma intrínseca relação homem e natureza.

\section{7- $\quad$ Referências Bibliográficas}

BERTONI, J.; LOMBARDI NETO, F. Conservação do Solo. $3^{\text {a }}$ edição. São Paulo: Ícone Editora, 1990.

BITTAR,Y.,et al. (1990). O meio Físico em Estudos de Impacto Ambiental. São Paulo: IPT, (Boletim, 56).

EMBRAPA, EMPRESA BRASILEIRA DE PESQUISA AGROPECUÁRIA. Serviço Nacional de Levantamento de Conservação de Solos. Manual de Métodos de Análises de Solos, v.1, Rio de Janeiro, 1997.

FONSECA, M. J. G., SILVA, Z. C. G., CAMPOS, D. A. \& TOSATOO, P. Carta Geológica do Brasil ao Milionésimo (Folhas de Rio de Janeiro/Vitória/Iguape, SF-23/24 e SG-23): texto explicativo. Brasília: 1979.

GASPAR JUNIOR, L. A. Geologia Ambiental: Ensaios Químicos e Geotécnicos em Solos, UNIFAL, Alfenas, 2011.

GASPAR, Lineo; A. F. D. C. Varajão; M. H. O. Souza; M. M. T. Moreno. Estudo comparativo das argilas das olarias dos municípios de Alfenas e Areado, MG. Cerâmica 58 -2012, P. 404-411.

GUERRA, A.J.T. et. al. (Orgs.) Erosão e conservação dos solos: conceitos, temas e aplicações. Cap.7, Rio de Janeiro: Bertrand Brasil,1999.

GUERRA, A. J. T.; ALMEIDA, Josimar Ribeiro de ; ARAUJO, G. H. S. . Gestão Ambiental de Áreas Degradadas. 1. ed. Rio de Janeiro: Bertrand Brasil, 2005. v. 1. p 82-85 .

GRILO, R.C.; ENAMI, L. Gestão de bacias hidrográficas com o uso de modelo preditivo de erosão dos solos e sistemas de informação geográfica. UNAR, Araras, SP, v.2, n.1, p.21-33, 2008.

HASUI, Y. \&OLIVEIRA, M.A.F. DE. Província Mantiqueira. In: ALMEIDA, F.F.M. DE \& HASUI, Y. (Coords.), O pré-cambriano do Brasil. São Paulo: Editora Edgard Blucher, p. 308-344, 1984.

IPT (1989). Consolidação do projeto orientação para o controle à erosão no Estado de São Paulo:IPT

LAL, R. Erodibility and erosivity. In: LAL, R. et al. Soil erosion research methods. Washington: Soil and Water Conservation Society, 1988. 


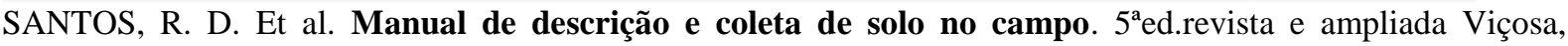
Sociedade Brasileira de Ciências de Solo, 2005. 100p 